\title{
Poéticas políticas, políticas poéticas: comunicação e sociabilidade nos coletivos artísticos brasileiros
}

\section{Fernando do Nascimento Gonçalves}

\section{Resumo}

0 presente texto é parte de uma pesquisa iniciada em 2009 que investiga as dinâmicas relacionais que envolvem a arte e usos de mídias nos espaços urbanos. Em particular, o artigo aborda as ações dos chamados "coletivos de artistas", grupos que atuam nos espaços públicos realizando intervenções que mesclam arte e ativismo de forma sensivelmente diferente dos anos 60 e 70. Baseando-se numa concepção conexionista e reticular, tais ações podem ser consideradas como uma prática social com interessantes aspectos comunicativos, na medida em que interconectam de forma inusitada espaços da cidade, tecnologias de comunicação, distintos atores sociais e formas artísticas. Em particular, o texto aborda as intervenções do grupo paulista Contra Filé e suas interseções com os movimentos sociais.

\section{Palavras-chave}

Comunicação. Sociabilidade. Arte. Cidade. Político.

Fernando do Nascimento Gonçalves I fng@uerj.com Professor e pesquisador da Faculdade de Comunicação Social e do PPGC-UERJ.

\section{Introdução}

0 presente artigo analisa as dinâmicas relacionais que envolvem a prática artística com tecnologias de comunicação nos espaços urbanos. Abordaremos especificamente as ações dos chamados "coletivos de artistas", práticas de intervenção em espaços públicos que mesclam arte e ativismo e se disseminam por meio de redes de virtuais e presenciais de comunicação. Nosso interesse aqui será abordar os aspectos relacionais e comunicativos dessas práticas, através das ações de alguns desses grupos; neste caso, o coletivo Contra Filé.

Os coletivos artísticos são grupos que trabalham no cruzamento entre ações de contestação e formas artísticas não convencionais. Inspirados pelos movimentos das vanguardas do começo do século XX e também por movimentos ligados à contracultura, suas ações consistem em trabalhos que algumas vezes se articulam com movimentos sociais, comunidades sem-teto, ativistas de mídia, intervenções urbanas.

Realizando ações em parte semelhantes às dos anos 60 e 70, os "coletivos artísticos" 
costumam atuar fora dos meios culturais institucionalizados. Contudo, seus modos de organização e de funcionamento apresentam também o que parecem ser descontinuidades com relação aos de épocas anteriores. Os coletivos surgidos no Brasil a partir dos anos 90 se inserem no contexto dos chamados "novos movimentos sociais" (GRANJON, 2001; GOHN, 2003; OFFE, 2003; CEFAI, 2007), nos quais se redefinem noções como "engajamento", "adesão" e "pertencimento", e o capital relacional se sobrepõe ao plano ideológico. Nesses grupos, as "identidades" de grupo são conjuradas e à formação de "comunidades" prefere-se a atuação em rede e a multiplicação de laços de solidariedade, frouxos, porém eficazes.

Categorizadas muitas vezes como práticas de "intervenção urbana" ou de "arte urbana", essas ações escapam, porém, às classificações e suscitam questionamentos relativos a nossos modos de vida, padrões e regras sociais. Nesse sentido, evocam um aspecto de alteridade que Janice Caiafa chamou de "comunicação da diferença" (CAIAFA, 2005). Na comunicação da diferença enfatiza-se não o reconhecimento dos códigos pelos sujeitos, mas seu estranhamento. Como prática social e de comunicação, consideramos que as ações dos coletivos evocam esse aspecto de alteridade, através de trabalhos que interconectam de forma inusitada espaços, formas artísticas, atores sociais e mídias.

Neste artigo, o foco repousará nas ações do coletivo Contra Filé, que realiza desde performances e instalações em locais públicos como praças, pontes e viadutos a intervenções junto a movimentos sociais como o dos "SemTeto", em São Paulo.

\section{Breve panorama das ações artísticas e políticas no espaço urbano}

Já no começo do século XX, dadaístas e surrealistas faziam dos espaços públicos um espaço de criação e de intervenção: ações marcadas por uma estética do choque, do escândalo, do inusitado (GLUSBERG, 1987; DE MICHELLI, 1991). Trata-se de movimentos de uma arte que então procurava romper com a representação e fundir-se com a vida, causando fissuras no pensamento sobre a própria experiência artística, visando a sua renovação, e com franca disposição para renovar também as relações entre homem e sociedade.

Mais tarde, nos anos 60 e 70, vemos grupos de artistas que se organizam nos Estados Unidos e na Europa para questionar códigos culturais, fazer protestos e promover uma forma de arte que desse sequência ao projeto de aproximação com o quotidiano, através de happenings, performances e manifestos, conjugados não raro com as lutas pelos direitos das minorias e contra a sociedade do espetáculo. No Brasil, particularmente, veremos no final dos anos 70, no contexto da abertura política e dos movimentos pela redemocratização do país, grupos nãohierarquizados como o "Viajou Sem Passaporte", "3Nós3" ou "Tupi Não Dá", discutindo questões 
ligadas aos direitos civis, mas também se interessando pelo questionamento de códigos culturais (MESQUITA, 2008, p. 232-233).

Os grupos surgidos nos anos 90 vão se constituir a partir de continuidades e descontinuidades com essas formas de arte e de engajamento político, baseadas em referenciais marxistas e situacionistas, da contracultura e da sociedade industrial. A partir desses referenciais, os "coletivos" vão de certa forma renovar uma atitude de resistência a um descrédito na política (mas não no político) e um certo "desinvestimento" da experiência do "público" - em função do privado - e do "coletivo" - em função do individual - observada nos anos 80 . Nesse sentido, os coletivos irão tentar realizar uma espécie de "reencantamento da participação social e política" (KELLENBERGER, 2000), que se traduz no uso de formas de intervenção pouco convencionais, embora não inéditas (artes plásticas, cênicas, corporais, reapropriações da mídia).

Percebe-se aí 0 que seria a atualização de um mesmo foco: as práticas e linguagens artísticas que emergem passam a ter uma atitude reflexiva e ativa sobre os problemas sociais contemporâneos: desemprego, exclusão, pobreza, abuso da publicidade, falta de moradia e também sobre certos aspectos materiais e subjetivos da vida nas cidades. Recursos como performances, instalações, colagens, fotografia, vídeo e também novas mídias irão revelar mais uma vez um aspecto potencialmente comunicativo.
Como em épocas anteriores, os coletivos vão hoje continuar a explorar a estética da ação coletiva, suas figuras, formas e signos e transformam a rua em espaço de prática crítica de deliberação, mobilização e releitura de códigos sociais. Mas, por outro lado, parece haver uma mudança no que poderíamos chamar de seu "projeto filosófico" e na concepção das formas de atuação. Diante do que se coloca como uma "crise dos modelos de representação política institucional" (OFFE, 2003), artistas e ativistas continuarão a atuar, mas suas formas de mobilização se inspirarão mais na perspectiva do "do it yourself", como reflexo da reorganização da sociedade civil, do que nos modelos formalístico dos movimentos dos anos 60 e 70. Os contornos das "comunidades políticas" desse período (partidos, sindicatos, redes de militantes) são questionados.

Os artistas e ativistas dos chamados "novos movimentos sociais" (MELUCCI, 1999; CEFAI, 2007) se interrogam precisamente sobre alguns dos elementos que constituem formas as institucionais de representação: códigos e papéis bem definidos e que formalizam a experiência de pertencimento e hierarquia, os repertórios de ação, os modos de formalização dos discursos. Esse gênero de interrogação coloca os coletivos na linha de emergência de formas que se propõem como mais diretas e ágeis de participação política e social. Trata-se de formas "reticulares", baseadas em coalizões temporárias e ações organizadas em rede por atores diversos e não mais propriamente no formato de uma 
organização formal e centralizada. Interpelandonos de forma crítica e muitas vezes lúdica, esses grupos existiam no Brasil já nos anos 70, teriam desaparecido nos anos 80 e reaparecido em meados dos anos 90 (ROSAS, 2003), tendo se multiplicado a partir dos anos 2000. Atualmente, contam-se às dezenas.

\section{Laço frouxo e a lógica de rede}

No Brasil, os "coletivos" podem ser formados tanto por artistas quanto por ativistas ou por pessoas simplesmente interessadas em participar. Para a maioria, o que importa são as "ações". Portanto, se, por um lado, noções como "mobilização política", "arte urbana" e "ativismo" se aplicam a esses grupos, por outro, eles não constituem propriamente uma forma de ativismo ou um movimento social ou artístico, embora possam eventualmente estar ligadas a movimentos diversos em função das ações realizadas. Precisamente, o que parece caracterizá-los é um "intervencionismo" que se dá em um regime de impermanência, de contrato flexível, que se distancia de formatos associativos rígidos e também da conjuração da cristalização de uma linguagem e de um modo operativo.

Trata-se de um modelo de participação por "projeto" e não por "plano", como definiu Fabien Granjon, no qual a ação coletiva não implica rigidez identitária, mas "multiplicidade de dispositivos transitórios" (GRANJON, 2001, p. 40). Nesse modelo, que segue uma lógica de rede, noções como "adesão" e "engajamento" se tornariam mais flexíveis, pois o "laço frouxo" e o princípio da afinidade são considerados elementos táticos que permitem "uma democracia de escolha de uma ação e não da escolha coletiva que determina o que farão juntos esse ou aquele indivíduo, essa ou aquela estrutura" (GRANJON, 2001, p. 40).

A nova geração de artistas e de ativistas tem uma compreensão bastante clara da importância das tecnologias de comunicação e das chamadas "redes sociais" para a troca de informação e para ampliar os repertórios de ação (SCHERERWARREN, 1993; GRANJON, 2001; BLONDEAU, 2007). Eles percebem que, em um mundo cada vez mais interligado, espaços presenciais e virtuais se imbricam através de redes de comunicação que passam a ser um importante recurso para novas formas de expressão artística e política. Atuando de forma independente ou por vezes de forma conjunta, muitos coletivos se inserem em redes virtuais de comunicação, por meios das quais realizam debates, trocam experiências e organizam ações conjuntas. São exemplos no Brasil: C.0.R.0. Coletivo, VIZINHOS e BASE; e ainda festivais de mídia e de intervenção urbana como a "Semana EIA de Imersão Ambiental", o "Festival ReverberAções" e 0 Festival Submidialogia.

0 modelo da rede implica a um só tempo uma lógica operativa e uma forma de organização social, como demonstrou Antoun (2004). Como forma de organização social, apresenta um 
aspecto flexível, reticular e policêntrico com adesão por afinidade e sem vínculos rígidos. Como lógica operativa, apresenta um aspecto de descentralização e mobilidade, com ações pontuais e efêmeras. Esse modelo foi adotado como "tática de guerra" por diversas organizações políticas nos anos 60 e hoje inspira movimentos sociais e coletivos. Esse modo operativo é observável notadamente na realização das práticas desses grupos, que são elas próprias muitas vezes a extensão ou a constituição mesma de uma rede: rede de ações, atores, situações e momentos, que se enredam e produzem, no instante, uma potência.

Um exemplo são as ações do grupo EIA (Experiência de Imersão Ambiental), criado em 2004 em São Paulo. Além da ação direta, o grupo organiza anualmente a "Semana EIA de Imersão Ambiental", que reúne projetos de intervenção de todo país para atuação em bairros do centro e da periferia de São Paulo. A ideia é "aprofundar a relação com a cidade e transformar o espaço público em 'laboratório de vivências sócio política e ambientais'1. Já em 2006, o evento e os projetos passaram a ser organizados presencialmente e à distância, por meio de blogs e listas de discussão na internet. A organização começa nos meses que antecedem 0 encontro por meio de debates e discussões em São Paulo e no blog criado pelo grupo, que não é apenas uma ferramenta de comunicação, mas um outro espaço de atuação que facilita a organização dos projetos:

\begin{abstract}
Apresentamos aos interessados contextos específicos mapeados [...] e reforçamos a intenção de aprofundar a ação coletiva urbana, potencializar a intensidade do encontro, além de estabelecer laços com projetos já em andamento em regiões específicas repensando nossa prática na cidade [...] Sugerimos zonas de ação para que os proponentes tenham mais informações para elaborarem projetos que fomentem a participação coletiva e 0 fortalecimento do espaço público. Estes mapeamentos e informações das zonas de ação poderão ser obtidos no blog http://mapeia.blogspot.com. Esses contextos devem ser levados em consideração na elaboração dos projetos [...] (EXPERIÊNCIA DE IMERSÃO AMBIENTAL, 2008)
\end{abstract}

Grupos como o EIA buscam instaurar uma "cultura de ação" nos espaços públicos, introduzindo novos signos no debate público sobre a vida nas cidades. Essa cultura se forma na confluência de duas tradições distintas: a "arte urbana" e as "práticas artísticas coletivas". De um lado, a chamada "arte urbana" (PALLAMIN, 1998) trabalha ao nível da vivência e da memória dos espaços, sua ressignificação, a consciência do instante, do emocional, dos efeitos de um estranhamento tomando por base os espaços da cidade. De outro, as "práticas artísticas coletivas" valorizam atuações baseadas num "contrato solidário" entre indivíduos e grupos, que levam em conta semelhanças e diferenças de experiências pessoais e habilidades de cada um (MESQUITA, 2008). Juntas, conferem uma 
potência de alteridade às práticas dos coletivos.

A lógica que impera nesse gênero de prática social é precisamente a da rede e a do "laço frouxo": 0 reticular, o conexionismo, os engajamentos flexíveis, a adesão por afinidades e não por ideologia. Tal lógica pode ser entendida pelas noções maffesolianas da socialidade e da razão sensível, na qual o emocional e a partilha dos sentimentos regem os encontros, formam e cimentam os laços sociais e forjam o sentido de pertencimento de grupo (MAFFESOLI, 1991). São esses conceitos que nos permitem entender também o princípio da "centralidade subterrânea" (MAFFESOLI, 2003) que preside os movimentos da vida social e que não são iluminados nem valorizados pela lógica social dominante e que nem por isso deixam de operar e definir modos de vida e formas sociais.

A lógica do "laço frouxo" indica a saturação da noção tradicional de "política" apontada por Maffesoli (1992), que baseia-se na nãoinstitucionalização das energias vitais que organizam a experiência social. Para o autor, trata-se de considerar o político não como representação da polis, mas como potência, no sentido empregado por Nietzsche. Baseados no que poderíamos considerar uma lógica de ação reticular e conexionista, os coletivos tentam hoje recolocar duas questões que se imbricam: a renovação de formas de engajamento e de ação política e a renovação das formas de inserção da arte no contexto de dissolução das fronteiras entre arte e vida.

\section{0 caso do coletivo "Contra Filé"}

Ruas, praças, parques, locais associativos e seu cotidiano interpelam os coletivos, envolvendo-os numa dinâmica particular. As "obras-ações" surgidas nesse contexto costumam ser realizadas segundo o princípio da "afinidade específica e temporária": membros de um grupo podem participar de mais de um projeto, inclusive do de outros coletivos. É o funcionamento "conexionista" e "reticular" da organização em rede, da qual essas práticas são um exemplo e, ao mesmo tempo, a base dessas formas de criação e de mobilização social.

É nesse contexto que se insere 0 Contra Filé. 0 grupo foi formado "oficialmente" em 2003, durante o Festival de Mídias Táticas, que reuniu coletivos de arte e ativismo de mídia na Casa das Rosas, em São Paulo. Descrevendo-se como "um grupo de investigação e produção de arte que trabalha a partir de sua experiência cotidiana na cidade de São Paulo", o Contra Filé surgiu da fusão de parte do antigo grupo $\mathrm{Mico}^{2}$, criado em 2000, com outros participantes presentes nesse evento. Do Mico, o Contra Filé manteve a preocupação com questões urbanas e políticas, 
que se misturariam com as questões artísticas, de modo a intensificar potência estética das ações.

Em 2004, o grupo foi convidado a participar do evento Zona de Ação, realizado em São Paulo, em parceria com o SESC-Paulista, como parte das atividades do Fórum Cultural Mundial. 0 projeto do evento foi proposto por diversos coletivos e contou com a participação de Suely Rolnik e do teórico e ativista de mídia Brian Holmes, que acompanharam o processo e 0 desenvolvimento das ações dos coletivos. A ideia do evento era que cada grupo investigasse uma das regiões da cidade (norte, sul, leste, oeste e centro) e propusesse uma ação local. 0 Contra Filé optou por trabalhar na zona leste.

Curiosamente, no início, o grupo diz ter tido resistência para trabalhar com esta parte da cidade, que lhes era totalmente desconhecida. Questionando esse sentimento, o grupo compreendeu que provavelmente se tratava de algo mais do que a simples distância e pensou na imagem da "catraca" como um símbolo de algo que "emperra um fluxo". Reuniu-se então com a equipe do Sesc Itaquera e conseguiu conversar com alguns moradores da região, com os quais iniciou um convívio e a uma discussão sobre a questão: "cada participante foi dando exemplos concretos de experiências, como nos ônibus, nos espaços culturais onde muitos são gratuitos, mas as pessoas não entram porque parece que tem uma catraca invisível"
(MESQUITA, 2008, p. 384). Foram também

feitas assembleias para discutir o significado do termo, como explicam Cibele Lucena e Joana Katz, em entrevista a André Mesquita:

Houve quem enxergasse a catraca como símbolo de algo que emperra, dificulta. $E$ isso pode ser literal ou subjetivo. Existem "catracas" que impedem as pessoas de chegar fisicamente a um lugar, radiais, avenidas ou rodoanéis com trânsito difícil. Existem também as catracas sociais, as raciais e as históricas, que dificultam a vida de outras maneiras (apud MESQUITA, 2008, p. 383-384).

0 grupo propôs então, como ação, criar um programa para a "descatracalização da vida", algo como "torná-la mais simples e sem entraves". A intenção era tornar o programa uma ação social oficial. Para concretizar a ideia, alguém sugeriu a construção de um monumento à catraca, o que de fato foi feito. Comprou-se uma catraca num ferrovelho da região e criou o "Monumento à Catraca Invisível" (figura1), escultura que depois foi instalada anonimamente no Largo do Arouche, centro de São Paulo, e cuja misteriosa presença ninguém sabia explicar.

Os artistas contam que perceberam a ausência de uma escultura na praça e resolveram aproveitar para instalar o "monumento". Alguns passantes estranharam a presença da catraca no lugar e julgaram tratar-se de um ato de vandalismo. A polícia teria sido chamada. A imprensa ficou sabendo, noticiou o caso e a catraca virou fait divers. 0 grupo foi localizado e acabou assumindo a autoria da "obra". 


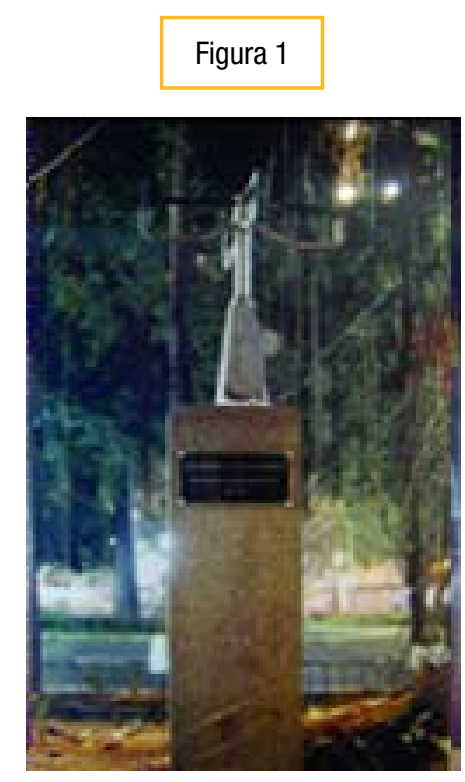

Fonte: Mesquita (2008, p. 266)

Porém, mais curiosa ainda foi sua repercussão. A matéria da Folha de São Paulo, tendo explicado que a catraca na verdade era uma obra de "arte" que simbolizava as formas de controle social, acabou inspirando que a mesma se tornasse em 2005 tema da redação da Fuvest, concurso que seleciona os futuros alunos da USP. A ação também desencadeou outras apropriações: foi tanto símbolo do protesto de estudantes contra 0 vestibular como forma de acesso à universidade, símbolo do movimento do "passe-livre" em Florianópolis, quanto slogan de campanha de um importante banco paulista, que propunha a prestação de serviços "descatracalizados".

Chama atenção no caso da "catraca" esse caráter de contágio próprio das ações de intervenção urbana, em que a experiência de comunicação não se reduz à midiatização dos fatos, mas consiste em um complexo processo que vai produção coletiva de uma ação e de sua transformação em "imagem" a suas diferentes formas de propagação e apropriação. É curioso observar como nesse gênero de ação produz-se um estranhamento apostando-se simplesmente em seu poder de reverberação. É que essas ações de intervenção possuem uma capacidade de reverberação importante: elas se encadeiam e podem engajar outros agentes, em outros contextos, mostrando que as ações cotidianas se interpenetram e afetam a todo instante, atravessando-nos também.

0 que importa para os coletivos é essa capacidade de gerar aquilo que Deleuze e Guattari (1992) chamaram de "afectos" e "perceptos". Estes elementos, explicam os autores, não se confundem com a sensação ou a percepção de algo que nos é exterior, mas consistem em uma espécie de relação de forças ou sensações que "podem tornar sensíveis forças insensíveis" (1992, p. 235) que nos afetam e transformam num nível sutil que é o das produções subjetivas. Para Deleuze e Guattari, o que os artistas fazem é "mostrar afetos e perceptos", ou seja, recortar ou "capturar pedaços do caos numa moldura" (ibid, p. 264). No caso, recortar pedaços de configurações da vida social para formar espécies de "imagens" sensíveis dessas configurações. É a partir desse trabalho com as "variabilidades" do mundo que, segundo os autores, os artistas vão acrescentar ao mundo novas variações.

É nesse espaço delicado que se dão os embates micropolíticos, que Guattari e Rolnik definiram 
como sendo da ordem das "formações do desejo no campo social" (1999, p.227).

Nota-se então que tais ações têm primordialmente esse caráter micropolítico de formação de desejo.

Contudo, elas podem também adquirir um caráter "macropolítico", através de sua instalação numa realidade "visível", como quando ganham notoriedade a partir de sua exposição na mídia ou em um lugar de grande circulação como estratégia de interpelação e de favorecer o contágio, embora aumente aí igualmente o risco de sua neutralização. Como as faixas rosa "instaladas" nos viadutos da cidade, o monumento à catraca invisível era uma "mensagem" que desejava desencadear uma outra ação: "trata-se da inscrição de um fato portador de futuro", como define Jerusa Messina, outra integrante do Contra Filé.

0 caso da "catraca" ilustra bem 0 aspecto relacional das ações dos coletivos e de suas ações, que podem encarnar situações-objeto, situações-vídeo ou performance, mas que na verdade condensa e enuncia todo um processo de criação coletiva e de produção de sentido. Como ato artístico, implica um processo conceitual e de construção simbólica e é exatamente por meio dos aspectos estético e comunicativo desse processo que este ato vai também expressar-se enquanto apropriação crítica, na esfera do ativismo.

É nesse registro, propriamente comunicativo, que Vera Pallamin inscreve os trabalhos de "arte urbana", que "permitem a apreensão de relações e modos diferenciais de apropriação do espaço urbano, envolvendo em seus propósitos estéticos o trato com significados sociais que as rodeiam, seus modos de tematização cultural e política" (1998, p. 24). É nesse registro também que Michel de Certeau (1994, p. 45) vai falar-nos da possibilidade de uma "politização das práticas cotidianas", através do deslocamento da ênfase na observação das representações sociais para os usos que podem ser feitos dessas representações, através de uma "estética da apropriação".

\section{Poéticas políticas, políticas poéticas: interseções com os movimentos sociais}

0 caso da "catraca" demonstra como os coletivos negociam em suas ações 0 estatuto das experiências do artístico e do político, na medida em que não apenas as "obras" não correspondem aos cânones da arte como também não têm a chancela das instituições que os legitimam. Ao mesmo tempo, enquanto "ação crítica", escapam aos modelos da "arte política" e do ativismo. Elas se produzem num interstício e formam um composto em que o político encarna o poético e vice-versa e em que uma instância não se reduz à outra, mas juntas produzem variações de uma e de outra.

Em suas análises sobre as relações entre arte e política, Suely Rolnik (2008) situa esse jogo de variações no campo da micro e da macropolítica. Para Rolnik, esses campos não se confundem, mas também não se opõem; antes, fazem parte de um mesmo movimento de liberação. Apesar disso, na história dos movimentos políticos e artísticos é possível observar momentos de 
encontro e de oposição entre ambos. Nem sempre se percebe que estes "compartilham a urgência de enfrentar as tensões da vida humana nos pontos em que sua dinâmica de transformação se encontra interrompida ou, no mínimo, esmaecida (ROLNIK, 2008, p. 3). Algumas vezes, por exemplo, no âmbito dos movimentos sociais e dos ativismos, não se percebe senão a dimensão macro da ação política, da mesma forma que na arte se privilegia muitas vezes a dimensão micropolítica. Segundo Rolnik (2008, p. 4), enquanto na ação macropolítica busca-se "trabalhar sobre as tensões que se inscrevem nas formas visíveis de dominação", na ação micro trabalha-se sobre "as tensões que operam no campo sensível das forças que nos atravessam no campo subjetivo". Com isso, algumas vezes não se percebe que a ação crítica, seja ela artística ou política, apresenta tanto dimensão micro quanto macro.

Contudo, em outros momentos, nada impede que um ou outro aspecto seja acentuado nessas ações. Como outros coletivos, o Contra Filé também "colabora" com os movimentos sociais. Nesses momentos, por exemplo, acentua-se claramente 0 aspecto macro de que nos fala Rolnik e estabelece-se uma tensão, não raro conflituosa, que não se controla, apenas se discute e negocia. Alguns grupos se dividem e às vezes alguns membros fazem escolhas entre atuar definitivamente mais numa instância ou em outra, formando outros coletivos. Outras vezes, o grupo como um todo decide atuar por determinando tempo mais em projetos de cunho "artístico" ou "político".

As ações do Contra Filé no movimento de mães de jovens da Febem, em 2005, e dos Sem-Teto, desde 2004, inserem-se nesse processo de negociação. 0 projeto "Rebelião das crianças" surgiu como uma forma de apoiar associações de defesa dos direitos da criança e do adolescente em situação de risco, como a AMAR. Através do "projeto", o coletivo realiza protestos de caráter performático com as mães dos "internos" da Febem de São Paulo.

As ações buscam discutir e denunciar 0 processo de criminalização do jovem no sistema correcional e na sociedade. Em particular, o grupo se interessa pelo modo como a mídia constrói e dissemina essa construção. 0 coletivo tenta compreender o significado do termo "rebelião" nos contextos da construção social e midiática da marginalidade e da exclusão:

$$
\begin{aligned}
& \text { Começamos olhando para as primeiras rebe- } \\
& \text { liões de abril de 2005, olhando para o jornal } \\
& \text { e vendo os discursos. } 0 \text { nome do projeto veio } \\
& \text { dessa ideia de deslocar esse nome 'interno'. } \\
& \text { Quando a gente lia no jornal 'interno', 'crimi- } \\
& \text { noso' e 'marginal' a gente trocava por 'criança' } \\
& \text { para ver o que acontecia [...] A gente olhava as } \\
& \text { imagens para ver como eles se comportavam } \\
& \text { fisicamente nas rebeliões, para entender o que } \\
& \text { é uma rebelião, como ela surge e por quê, se } \\
& \text { ela pode ser um momento de resistência e se } \\
& \text { ela pode lutar pelos direitos humanos (CONTRA } \\
& \text { FILÉ apud MESQUITA, 2008, p. } 389 \text { ) }
\end{aligned}
$$

Na interseção com essas associações, 0 coletivo diz assumir um papel de "produtor 

e de uma experiência de vida", participando de assembleias e conversas informais e colaborando na organização de manifestações (ibid, p.136 e 389). Um exemplo foi um protesto não-convencional em frente à Secretaria Municipal de Justiça em 2006. Contra Filé e AMAR organizaram uma festa infantil em que apresentaram performances, fotos e cartazes com dados oficiais sobre tortura e desvio de verba na Febem. Crianças, moradores de rua e organizadores "comemoraram" com uma mesa de refrigerantes, café e bolo a perda da infância simbólico de luta de um movimento organizado

de centenas de crianças, buscando ao mesmo tempo sensibilizar o público para a questão.

Outro movimento com o qual o Contra Filé "colaborou", desta vez de forma indireta, foi 0 MSTC, "Movimento dos Sem-Teto do Centro". 0 movimento faz parte das lutas contra 0 fenômeno da gentrificaçã $0^{3}$ e pelo direito à moradia. Um "símbolo" dessa luta foi a ocupação do Prestes Maia, prédio abandonado que se tornou moradia para centenas de famílias no centro da cidade e que foi objeto de reintegração de posse entre 2002 e 2006. Muitos desses grupos justificaram sua participação "na

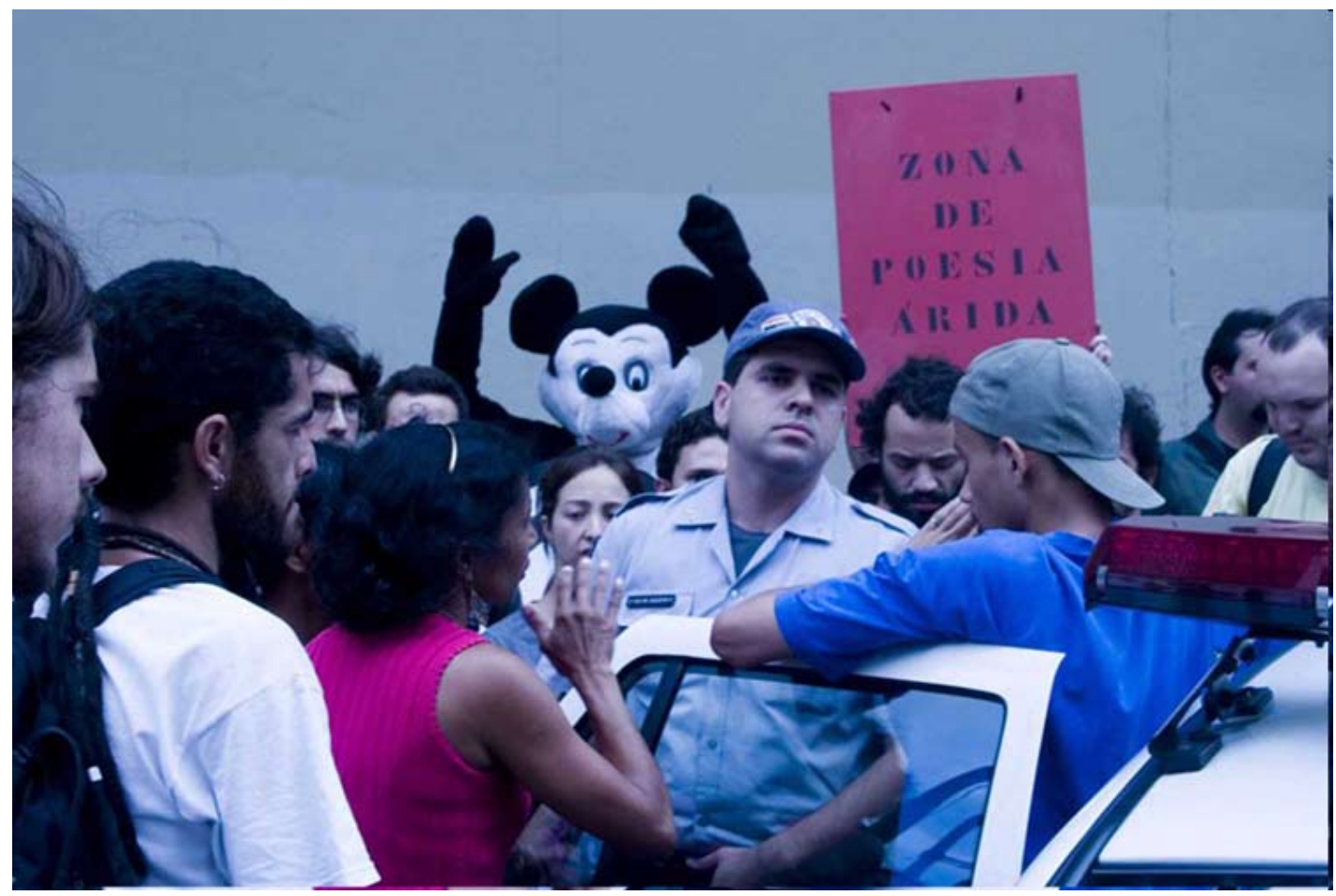

Fonte: Mesquita, 2008.

Processo em que ocorre uma valorização imobiliária de determinada área por meio de reforma e melhorias de infraestrutura que terminam por "expulsar" a população local e atrair uma população de classe média-alta. 
ocupação" como uma questão de "urgência de vida". 0 Prestes Maia significava para alguns deles um espaço "árido", onde as pessoas e as coisas "foram embrutecendo".

A noção de "aridez" surgiu de um trabalho do coletivo Cia. Cachorra, realizado com prostitutas no Parque da Luz. No convívio e nas conversas, as artistas perceberam "que o lugar tinha afetos e poesia" e resolveram chamá-lo de "Zona de Poesia Árida", pois "a poesia existe, mas não tem água pra viver". A ação desenvolvida foi colocar no parque uma placa com a frase "Zona de Poesia Árida" e entregar cartões e rosas vermelhas para as prostitutas. Foram confeccionados barquinhos de papel para serem dados junto com as rosas. Cada prostituta foi convidada a escrever um sonho em seu barquinho e colocá-lo no lago do parque. Mas quando chegaram lá o lago estava vazio. Mesmo assim, depositaram seus barcos no leito vazio, na lama que restava no fundo. "Os sonhos daquelas mulheres, na maioria senhoras de 50 anos, eram os mesmos que os nossos, como ter uma casa, um amor, ver o filho, voltar a estudar. Uma mulher disse: 'sonho em voltar a sonhar"' (CIA. CACHORRA apud MESQUITA, 2008, p. 400). 0 trabalho, que "investigava a aridez que fica impregnada nas relações", foi realizado na ocupação, também uma "Zona de Poesia Árida" (Foto 2 - Fonte: MESQUITA, 2008).

Essas e outras ações foram desenvolvidas no Prestes, como festas, assembleias, exposições, performances. Mas, uma vez inserida num movimento organizado, a participação dos coletivos não se reduziu a "regar" a ocupação com poesia. Alguns se uniram aos moradores para enfrentar a polícia, improvisando barricadas e faixas e até levando alimentos e roupas.

Em entrevista a André Mesquita, o Contra Filé afirma não ter participado diretamente do movimento, tendo apenas colaborado com os outros coletivos, com a presença de alguns de seus membros. Afirma que o movimento não fazia parte do processo do grupo naquele momento, mas apoiou, por exemplo, a exposição "Território São Paulo", improvisada em uma das dependências do Prestes em 2006. A exposição fora inicialmente prevista para acontecer na $9^{\mathrm{a}}$ Bienal de Havana, mas acabou acontecendo em São Paulo. Convidados oficialmente "em cima da hora", os coletivos não conseguiram viabilizar sua ida até Cuba e resolveram expor seus trabalhos dentro do prédio, o que aumentou a atenção pública sobre a ocupação. 0 resultado foi talvez a maior obra de arte da Bienal fora da Bienal: 0 adiamento do despejo das mais de 450 famílias.

\section{Considerações finais}

Experimentações situadas nos campos das micro e das macropolíticas, as práticas dos coletivos artísticos são mais que um modismo veiculado pela mídia ("artivismo") ou uma nova tendência da arte contemporânea ("arte urbana"). Tratase de um fenômeno com inscrições históricas bem precisas em que a intervenção nos espaços urbanos é ao mesmo tempo um ato 
artístico, político e comunicativo. Tais práticas problematizam não apenas o contexto em que são realizadas, mas também o estatuto e a autonomia do trabalho de arte, além de permitir pensar novas formas de ação coletiva.

Os grupos encontram nas próprias contradições da cidade o próprio material social e estético para seus projetos (ROSAS, 2003). Seu trabalho consiste em observar e identificar rupturas que produzam dissonâncias e reverberações que favoreçam o diálogo, a ação coletiva e 0 debate dos temas sociais. 0 que as ações como as do Contra Filé parecem tentar fazer é precisamente isto: criar um espaço de diálogo ou de conjugação das instâncias micro e macropolítica, garantindo para essas práticas uma transversalidade e uma potência transformadora.

Para tanto, como afirmava Ricardo Rosas, importa tanto considerar uma "renúncia" à Arte com A maiúsculo para realizar uma "arte" com a minúsculo, mais próxima à vida, quanto considerar, no campo do ativismo, uma renúncia a um didatismo que por vezes se torna estéril e conservador à força de querer libertar. Rosas defende que essa aproximação entre arte, vida e política implicaria antes uma potencialização do estético e não seu empobrecimento. Implicaria também uma ampliação da noção de "arte" como experiência de criação e do "artista", que nesse contexto poderia ser compreendido como "pensador, criador de estratégias de ação, arquiteto de atos que vão reverberar".
Certas ações poderiam parecer simples à primeira vista, mas teriam um valor estético potencialmente transformador, na medida em que atuam diretamente sobre o campo da produção de sentido, produzindo estranhamento. Uma performance de um exército de executivos (Esqueleto Coletivo e EIA, 2003) ou a mudança do nome da avenida Roberto Marinho para avenida Vladimir Herzog, no centro de São Paulo (Centro de Mídia Independente, 2000): todas são ações que podem não passar por "Arte" nos cânones vigentes, mas seu poder simbólico é tal que servem para inspirar mais táticas conceituais que desmantelem 0 arcabouço mental dominante" (ROSAS, 2003). Da mesma forma, no encontro com a potência artística, a dimensão político-ativista é renovada, sobressaindo seu aspecto estético e criativo.

Finalmente, o que sobressai dessas práticas é 0 favorecimento da irrupção de uma potência transformadora que se encarna em ações de arte $e$ de ativismo. Constituídas num interstício, essas ações podem ser consideradas como um ato ao mesmo tempo político, artístico e de comunicação, pelo trabalho de articulação criadora e de variação com essas instâncias micro e macropolíticas.

Um dos aspectos que ajuda a compor essas articulações, como tentamos mostrar, é a sociabilidade, fundada ela própria numa experiência de circulação e de articulação combinatória. As práticas dos coletivos apresentam um aspecto relacional que 
se expressa não apenas em seus modos de organização enquanto grupo, como também em suas estratégias e recursos. Interessante observar que - para muitos desses grupos eventos, reuniões com moradores, encontros com passantes, intervenções, blogs e listas de discussão na internet aparentemente têm um mesmo status ou uma mesma importância: a de viabilizar encontros e enfrentamentos. Tais recursos correspondem ao que Guattari chamou de "objetos ambíguos", elementos que apresentam uma lógica de auto-referência e uma função transversal que "Ihes permite atravessar as circunscrições de tempo e de espaço e de transgredir marcas identitárias" (Guattari, 2008, p. 132). São todos formas ou elementos extraídos do cotidiano e que são articulados e combinados de modo a produzir instantes provisórios mas oportunos e com potência estética, política e comunicativa.

Nesse sentido, no contexto dos coletivos, a produção artística entendida como prática simbólica pode ser importante para uma disseminação de um ruído, de uma dissonância. Precisamente nesse processo de disseminação vejo uma figura da comunicação da diferença de que nos fala Caiafa (2005). Nesse gênero de experiência de comunicação, o que se produz não são signos que remetem a operações de reconhecimento, mas uma experiência de alteridade. Um pluralismo que incorpora, reprocessa elementos da cultura e produz mecanismos que permitem afirmar uma potência de vida.

\section{Referências bibliográficas}

ANTOUN, Henrique. Democracia, multidão e guerra no ciberespaço. In: PARENTE, André (org.). Tramas da rede. Porto Alegre : Sulina, 2004.

BLONDEAU, Olivier. Devenir média. Paris: Éditions Amsterdam, 2007.

CAIAFA, Janice. Produção comunicativa e experiência urbana. In: CONGRESSO NACIONAL DA SOCIEDADE DE ESTUDOS INTERDISCIPLINARES EM

COMUNICAÇÃO, 18., 2005, Rio de Janeiro. Anais... Rio de Janeiro : Intercom, 2005.

CEFAI, Daniel. Pourquoi se mobilise-t-on? Paris: La Découverte, 2007.

DE CERTEAU, Michel. A invenção do cotidiano. Petrópolis: Vozes, 1994.

DELEUZE, Gilles; GUATTARI, Félix. 0 que é a

Filosofia? Rio de Janeiro: 34, 1992.

DE MICHELI, Mario. As vanguardas artísticas. São Paulo: Martins Fontes, 1991.

\section{EXPERIÊNCIA DE IMERSÃO AMBIENTAL. Jogo}

EIA 2008. Disponível em: < http://mapeia.wordpress. com/2008/11/06/hello-world/>. Acesso em 03/12/2008.

GOHN, Maria da G. Movimentos sociais no início do século XXI. Petrópolis: Vozes, 2003.

GLUSBERG, Jorge. A arte da performance. São Paulo: Perspectiva, 1987.

GRANJON, Fabien. L'internet militant. Paris : Apogée, 2001.

GUATTARI, Félix. Du postmoderne au postmédia. Multitudes, Paris, n.34, p. 128-134, set. 2008. ; ROLNIK, Suely. Micropolítica. Petrópolis: Vozes, 1999.

KELLENBERGER, Sonja. Espaces publics et formes de mobilisation politique: le rôle des pratiques 
artistiques. Paris : Programme Culture, ville et dynamiques sociales, 2000.

MAFFESOLI, Michel. Notes sur la postmodernité. Paris: Félin, 2003.

La transfiguration du politique. Paris, Grasset, 1992.

. Le temps des tribus, le déclin de

l'individualisme dans les sociétés de masse. Paris :

Les Livre de Poches, 1991.

MESQUITA, André. Insurgências poéticas: arte ativista e ação coletiva. 2008. Dissertação (Mestrado em História) - Departamento de História Social, Universidade de São Paulo, São Paulo, 2008.

MELUCCI, Alberto. Mouvements, crise de la politique et nouveaux militants. Paris : La Découverte, 1999.

PALLAMIN, Vera M. Arte Urbana. São Paulo: Annablume, 1998.

OFFE, Claus. Les nouveaux mouvements sociaux : un défi aux limites de la politique institutionnelle. Multitudes Web, Paris, n.22, 2003. Disponível em: $<$ http://multitudes.samizdat.net/article.php3?id_ article $=945>$. Acesso em: 23 jun 2008 .

ROLNIK, Suely. Desentranhando futuros. Revista Eletrônica de Jornalismo Científico, São Paulo, n. 99, jun. 2008. Disponível em: <http://www.comciencia. $\mathrm{br} /$ comciencia/handler.php?section $=8 \&$ edica $0=36 \&$ id $=423>$. Acesso em: 12 jul 08 .

ROSAS, Ricardo. Notas sobre o coletivismo artístico no Brasil. Trópico, São Paulo, n. 4, 2005. Disponível em: $<$ http://pphp.uol.com.br/tropico/html/textos/2578,1. shl>. Acesso em: 22 jan 2006.

SCHERER-WARREN, Ilse. Redes de movimentos sociais. São Paulo: Loyola, 1993. 
Poetical politics, political poetics: communication and sociability in Brazilian artistic collectives

Poéticas políticas, políticas poéticas: comunicación y sociabilidad en los colectivos artísticos brasileños

\section{Abstract}

This article is part of a research that has started in 2009 and that analyzes the relational dynamics involving art and media technology uses of in urban space. This article particularly focuses on the actions of so-called "collective of artists", groups which operate in public spaces making interventions that mix art and activism in a quite different fashion if compared to those of the 1960's and the 1970's. Based on a connectionist design and networking, these actions can be considered a social practice with interesting communicative aspects since they interconnect urban spaces, media technology, different social actors and artistic forms in an unusual way. In particular, the text addresses the operations of the group Contra Filet from São Paulo and their intersection with social movements.

\section{Keywords}

Communication. Sociability. Art.

Urban space. Political.

\section{Resumen}

Este artículo es parte de una investigación iniciada en 2009, cuyo objeto es investigar las dinámicas relacionales que involucran el arte y los usos de las tecnologías de comunicación en el espacio urbano. Este artículo se centra particularmente en las acciones de los llamados "colectivos de artistas", grupos que operan en los espacios públicos mezclando arte y activismo pero de una forma sensiblemente diferente de aquella de las décadas de 1960 y 1970. Basado en un diseño conexionista y de redes, estas acciones pueden ser consideradas como una práctica social con interesantes aspectos comunicativos, por su inusual forma de articulación de espacios urbanos, tecnologías de comunicación, diferentes actores sociales y formas artísticas. En particular, el texto aborda las acciones del grupo Contra Filé, de São Paulo, y su intersección con los movimientos sociales. .

\section{Palabras clave}

Comunicación. Sociabilidad. Arte.

Espacio urbano. Político. 


\section{Expediente}

A revista E-Compós é a publicação científica em formato eletrônico da Associação Nacional dos Programas de Pós-Graduação em Comunicação (Compós). Lançada em 2004, tem como principal finalidade difundir a produção acadêmica de pesquisadores da área de Comunicação, inseridos em instituições do Brasil e do exterior.
E-COMPÓS I www.e-compos.org.br I E-ISSN 1808-2599

Revista da Associação Nacional dos Programas de Pós-Graduação em Comunicação. Brasília, v.13, n.1, jan./abr. 2010.

A identificação das edições, a partir de 2008 passa a ser volume anual com três números.

\section{CONSELHO EDITORIAL}

Afonso Albuquerque

Universidade Federal Fluminense, Brasil

Alberto Carlos Augusto Klein

Universidade Estadual de Londrina, Brasil

Alex Fernando Teixeira Primo

Universidade Federal do Rio Grande do Sul, Brasil

Alfredo Vizeu

Universidade Federal de Pernambuco, Brasil

Ana Carolina Damboriarena Escosteguy

Pontifícia Universidade Católica do Rio Grande do Sul, Brasil

Ana Silvia Lopes Davi Médola

Universidade Estadual Paulista, Brasil

André Luiz Martins Lemos

Universidade Federal da Bahia, Brasil

Ângela Freire Prysthon

Universidade Federal de Pernambuco, Brasil

Antônio Fausto Neto

Universidade do Vale do Rio dos Sinos, Brasil

Antonio Carlos Hohlfeldt

Pontifícia Universidade Católica do Rio Grande do Sul, Brasil

Arlindo Ribeiro Machado

Universidade de São Paulo, Brasil

César Geraldo Guimarães

Universidade Federal de Minas Gerais, Brasil

Cristiane Freitas Gutfreind

Pontifícia Universidade Católica do Rio Grande do Sul, Brasil

Denilson Lopes

Universidade Federal do Rio de Janeiro, Brasil

Eduardo Peñuela Cañizal

Universidade Paulista, Brasil

Erick Felinto de Oliveira

Universidade do Estado do Rio de Janeiro, Brasil

Francisco Menezes Martins

Universidade Tuiuti do Paraná, Brasil

Gelson Santana

Universidade Anhembi/Morumbi, Brasil

Goiamérico Felício

Universidade Federal de Goiás, Brasil

Hector Ospina

Universidad de Manizales, Colômbia

Herom Vargas

Universidade Municipal de São Caetano do Sul, Brasil

leda Tucherman

Universidade Federal do Rio de Janeiro, Brasil

Itania Maria Mota Gomes

Universidade Federal da Bahia, Brasil

Janice Caiafa

Universidade Federal do Rio de Janeiro, Brasil

Jeder Silveira Janotti Junior

Universidade Federal da Bahia, Brasil
João Freire Filho

Universidade Federal do Rio de Janeiro, Brasil

John DH Downing

University of Texas at Austin, Estados Unidos

José Luiz Aidar Prado

Pontifícia Universidade Católica de São Paulo, Brasil

José Luiz Warren Jardim Gomes Braga

Universidade do Vale do Rio dos Sinos, Brasil

Juremir Machado da Silva

Pontifícia Universidade Católica do Rio Grande do Sul, Brasil

Lorraine Leu

University of Bristol, Grã-Bretanha

Luiz Claudio Martino

Universidade de Brasília, Brasil

Maria Immacolata Vassallo de Lopes

Universidade de São Paulo, Brasil

Maria Lucia Santaella

Pontifícia Universidade Católica de São Paulo, Brasil

Mauro Pereira Porto

Tulane University, Estados Unidos

Muniz Sodre de Araujo Cabra

Universidade Federal do Rio de Janeiro, Brasil

Nilda Aparecida Jacks

Universidade Federal do Rio Grande do Sul, Brasil

Paulo Roberto Gibaldi Vaz

Universidade Federal do Rio de Janeiro, Brasil

Renato Cordeiro Gomes

Pontifícia Universidade Católica do Rio de Janeiro, Brasil

Ronaldo George Helal

Universidade do Estado do Rio de Janeiro, Brasil

Rosana de Lima Soares

Universidade de São Paulo, Brasil

Rossana Reguillo

Instituto Tecnológico y de Estudios Superiores do Occidente, México

Rousiley Celi Moreira Maia

Universidade Federal de Minas Gerais, Brasil

Samuel Paiva

Universidade Federal de São Carlos, Brasil

Sebastião Albano

Universidade Federal do Rio Grande do Norte, Brasil

Sebastião Carlos de Morais Squirra

Universidade Metodista de São Paulo, Brasil

Simone Maria Andrade Pereira de Sá

Universidade Federal Fluminense, Brasil

Suzete Venturelli

Universidade de Brasília, Brasil

Valério Cruz Brittos

Universidade do Vale do Rio dos Sinos, Brasil

Veneza Mayora Ronsini

Universidade Federal de Santa Maria, Brasil

Vera Regina Veiga França

Universidade Federal de Minas Gerais, Brasil

\section{COMISSÃO EDITORIAL}

Felipe da Costa Trotta I Universidade Federal de Pernambuco, Brasil Rose Melo Rocha I Escola Superior de Propaganda e Marketing, Brasil CONSULTORES AD HOC

João Maia I Universidade do Estado do Rio de Janeiro, Brasil Sandra Gonçalves I Universidade Federal do Rio Grande do Sul, Brasil Mayra Rodrigues Gomes I Universidade de São Paulo, Brasil Gisela Castro I Escola Superior de Propaganda e Marketing, Brasil João Carrascoza I Escola Superior de Propaganda e Marketing, Brasil Luciana Pellin Mielniczuk I Universidade Federal de Santa Maria, Brasil Irene de Araújo Machado I Universidade de São Paulo, Brasil Hermilio Pereira dos Santos Filho I Pontifícia Universidade Católica, Brasil Benjamim Picado I Universidade Federal Fluminense, Brasil Maria Apaecida Baccega I Escola Superior de Propaganda e Marketing, Brasil Rogério Ferraraz I Universidade Anhembi Morumbi, Brasil

Bruno Souza Leal I Universidade Federal de Minas Gerais, Brasi REVISÃO DE TEXTO E TRADUÇÃo I Everton Cardoso EDITORAÇ̃̃ ELETRÔNICA I Roka Estúdio
COMPóS I www.compos.org.br

Associação Nacional dos Programas de Pós-Graduação em Comunicação

Presidente

Itania Maria Mota Gomes

Universidade Federal da Bahia, Brasil

itania@ufba.br

Vice-presidente

Julio Pinto

Pontifícia Universidade Católica de Minas Gerais, Brasil juliopinto@pucminas.br

Secretária-Geral

Ana Carolina Escosteguy

Pontifícia Universidade Católica do Rio Grande do Sul, Brasil carolad@pucrs.br 